DR GUANG-QIAN XIAO (Orcid ID : 0000-0003-2111-5897)

Article type : Original Article

\title{
ZBTB16 is a sensitive and specific marker in detection of metastatic and extragonadal yolk sac tumor
}

Guang-Qian Xiao ${ }^{1}$, David S. Priemer ${ }^{2}$, Christina Wei ${ }^{1}$, Manju Aron ${ }^{1}$, Qi Yang ${ }^{3}$, Muhammad T. Idrees $^{2}$
${ }^{1}$ Department of Pathology, Keck Medical Center of the University of Southern California, Los Angeles, CA
${ }^{2}$ Department of Pathology, Indiana University, Indianapolis, IN.
${ }^{3}$ Department of Pathology, University of Rochester Medical Center, NY
Corresponding author:

Dr. Guang-Qian Xiao

Department of Pathology

Keck Medical Center

University of Southern California

1500 San Pablo Street

Los Angeles, CA 90033

Email: guang-qian.xiao@med.usc.edu

Phone: 323-442-9610

Fax: 323-442-9993

This is the author's manuscript of the article published in final edited form as:

Xiao, G.-Q., Priemer, D. S., Wei, C., Aron, M., Yang, Q. and Idrees, M. T. (2017), ZBTB16 is a sensitive and specific marker in detection of metastatic and extragonadal yolk sac tumor. Histopathology. Accepted Author Manuscript. http://dx.doi.org/10.1111/his.13276 
Running title: ZBTB16 and yolk sac tumor

Conflict of Interest: None

\section{ABSTRACT}

AIMS: Accurate histologic diagnosis and classification of germ cell tumors (GCTs) is key to informing successful therapeutic and surveillance strategy. Modern therapeutic approach for yolk sac tumor (YST) is highly curative. Because YST takes on a large morphologic spectrum, it can be confused for other GCT subtypes as well as somatic carcinomas, particularly when YST presents in an extragonadal or a metastatic setting. Currently available immunohistochemical markers are limited by suboptimal sensitivity and specificity. We recently reported that ZBTB16 is a sensitive and specific marker for testicular YST. ZBTB16 is absent in other GCTs and in most common somatic carcinomas, including these of gastrointestinal, pancreatobillary, respiratory, genitourinary and gynecologic tracts. The purpose of this study is to investigate the diagnostic utility of ZBTB16 in the settings of metastatic and extragonadal YST.

METHODS AND RESULTS: We studied 32 archived metastatic and 4 extragonadal primary YSTs as well as 51 somatic malignancies for their immunohistochemical expression of ZBTB16. For comparison, AFP and Glypican-3 were also studied in parallel. Our results demonstrated an overall sensitivity of $91.6 \%$ for ZBTB16 in detecting metastatic and extragonadal YSTs. The non-YST elements (teratoma and embryonal carcinoma) in 15 YSTcontaining metastatic mixed GCTs were nonreactive. With exception of occasional myoepithelial cells of salivary gland carcinoma, all the 51 somatic malignancies were negative for ZBTB16.

This article is protected by copyright. All rights reserved. 
CONCLUSION: ZBTB16 is a sensitive and specific marker for YST and is diagnostically superior to AFP and Glypican-3 in metastatic and extragonadal settings.

Key words: ZBTB16, yolk sac tumor, metastatic, extragonadal

\section{INTRODUCTION}

Accurate histologic diagnosis and classification of germ cell tumors (GCTs) is key to informing successful treatment and surveillance strategy. Modern therapeutic approach for yolk sac tumor (YST) is highly curative with a survival rate of greater than $90 \%$ (1). Because it takes on a large morphologic spectrum, YST has been the most commonly underdiagnosed element among the testicular GCTs (2-4). It can be confused for other GCT subtypes as well as primary somatic neoplasms, particularly when YST presents as an extragonadal primary or as a metastasis to other organs. This could lead to improper selection of therapeutic as well as biochemical surveillance strategy. Several ancillary markers have been used to facilitate the diagnosis of GCT, including the early marker, like placental-like alkaline phosphatase (PLAP), and the more recent ones - OCT4, SOX2 and SALL4. Although these markers are sensitive for GCTs, they lack specificity for subtyping GCTs $(5,6)$. There are currently limited YST immunohistochemical markers. $\alpha$-fetoprotein (AFP) is a marker moderately specific for YST, but with a relatively low sensitivity, particularly for YST with glandular pattern (2-4). In addition, protein expression of AFP in YST may be lost in metastatic or post-treatment settings $(7,8)$. Furthermore, AFP is also expressed in some primary somatic neoplasms, such as hepatocellular carcinoma, hepatoid adenocarcinoma of the stomach, and clear cell carcinomas of mullerian origin (9-11). Another recently identified YST marker is GPC-3 $(12,13)$; however, its expression has been reported in other GCT subtypes, such as choriocarcinoma and, less frequently, teratoma and embryonal carcinoma $(12,13)$, as well as some primary somatic neoplasms $(12,14-17)$. Because of these limitations, a diagnostic 
immunohistochemical panel, including markers of pluripotentiality (SALL4 and LIN28) and endodermal identity (AFP, GPC-3 and villin), is recommended to overcome the diagnostic challenges of multiple patterns of differentiation in YSTs (18).

Zinc finger and BTB (Broad/complex/Tramtrack/Bric a Brac) domain containing 16 (ZBTB16) was first identified in a patient with acute promyelocytic leukemia. It is a zinc finger transcription factor belonging to the POZ (POxvirus and Zinc finger) -Krüppel family that binds to specific DNA sequences with its carboxy-terminal zinc fingers and suppresses transcription by recruiting co-repressors with its aminoterminal POZ domain (19, 20). ZBTB16 affects diverse signaling pathways, including cell cycle, differentiation, and programmed cell death pathways in hematopoietic cells as well as solid tumors (20-23). It is involved in major developmental and biological processes, such as spermatogenesis and stem cell maintenance, hind limb formation, hematopoiesis, immune regulation, and oncogenesis (19-21). In normal testes, ZBTB16 is expressed specifically in undifferentiated spermatogonial cells $(19,24)$. Studies have implied that ZBTB16 serves to promote spermatogonial stem cell self-renewal $(19,24)$ and plays a key role in the maintenance of normal spermatogenesis. Infertility is observed in ZBTB16-null mice due to the impairment of spermatogonial stem cell self-renewal and subsequent exhaustion of spermatogonia (24, 25). Although the function of ZBTB16 in spermatogenesis is relatively well studied, expression of ZBTB16 in GCTs has just been explored. We recently reported that, in testis, ZBTB16 is specifically expressed in YST, carcinoid and spermatocytic tumor but not in other GCT subtypes. Somatically, ZBTB16 is mainly expressed in prostate adenocarcinoma (23) and some carcinoid tumors (26). It is absent in most of the other common somatic tumors, including those of gastrointestinal, pancreatobillary, respiratory, genitourinary and gynecologic tracts (27).

This article is protected by copyright. All rights reserved. 
The aim of this study was to investigate the diagnostic utility of immunohistochemical expression of ZBTB16 in the detection of metastatic and extragonadal YSTs. The diagnostic value of ZBTB16 will also be compared against AFP and GCP-3.

\section{MATERIAL AND METHODS}

\section{Tissue samples}

This study was approved by the relevant institutional review boards. A total of 32 metastatic YST-containing GCTs and 4 extragonadal primary YSTs accessioned between 2010 - 2016 were retrieved from the archives of two academic institutions. Among the 32 metastatic GCTs, 17 were pure YSTs, and 15 were mixed GCTs containing 5\%-95\% of YST element. The non-YST components in the metastatic mixed GCTs included teratoma (13 cases) and embryonal carcinoma (6 cases). Of the metastatic YSTs, 24 were obtained prior to chemotherapy, 8 were recurrent YSTs after chemotherapy. Most of the YSTs exhibited multiple morphologies (e.g. cystic, glandular, papillary, and solid). The sites of the metastases included retroperitoneum ( 22 cases), mediastinum/neck ( 5 cases), lower abdomen and pelvis (5 cases), and lung ( 1 case). The primary non-testicular extragonadal YSTs included 1 mediastinal, 1 retroperitoneal, 1 liver and 1 urinary bladder primaries. All the extragonadal YSTs were pure YSTs. The diagnosis of YST was established by clinical history including serum markers, histomorphology and/ or the results of immunohistochemical markers - AFP, GPC-3, SALL4, OCT4, PLAP, CD117, D2-40, and /or CD30.

Besides the somatic tumors that we have previously studied $(23,27,28)$, fifty-one primary somatic malignancies, many of which exhibit morphologic overlap with YST, were evaluated for the immunohistochemical expression of ZBTB16. They included 8 breast carcinomas (4 ductal and 4 lobular carcinomas), 8 melanomas, 5 lymphomas (1 diffuse large 
cell lymphoma, 1 Hodgkin's lymphoma, 1 T cell lymphoma, 2 CD30-positive malignant lymphomas), 3 pancreatobiliary carcinomas, 6 combined small cell carcinomas and urothelial carcinomas of urinary bladder, 7 head neck carcinomas (1 poorly differentiated nonkeratinizing squamous cell carcinoma , 6 salivary gland carcinomas), 3 mesotheliomas, 2 synovial sarcomas, 2 renal cell carcinomas, 2 poorly differentiated carcinomas of mullerian origin, 2 colorectal carcinomas, 2 merkel cell carcinomas, and 1 adrenocortical carcinoma.

\section{Immunohistochemistry}

For ZBTB16 immunohistochemistry, following deparaffinization and rehydration, charged slides with 5 - $\mu \mathrm{m}$ thick sections of tissue were treated with $3 \%$ hydrogen peroxide $\left(\mathrm{H}_{2} \mathrm{O}_{2}\right)$ to eliminate endogenous peroxidase activity, then processed for antigen retrieval with 10-mM citrate buffer pH 6.0 using a pressure cooker (Pascal; Dako Cytomation, Glostrup, Denmark) for 1 minute at $125^{\circ} \mathrm{C}$, followed by slow cooling. The rest of the procedure was done in a DAKO automated instrument. All sections were rinsed with phosphate-buffered saline $(137 \mathrm{mM} \mathrm{NaCl}, 2.7 \mathrm{mM}$ potassium chloride, $4.2 \mathrm{mM}$ sodium phosphate, and $1.5 \mathrm{mM}$ potassium phosphate) and reacted with mouse anti-ZBTB16 antibody (D-9; sc-28319, Santa Cruz Biotechnology, Santa Cruz, CA) for 1.5 hours at 1:500 dilution in phosphate-buffered saline containing $1 \%$ bovine serum albumin (BSA) and 5\% normal goat serum at room temperature. The sections were then incubated for 20 minutes with EnVision+ System horseradish peroxidase-labeled polymer conjugated with biotinylated anti-mouse secondary antibody and 3,3'-diaminobenzidine substrate. Laboratory validated AFP and GPC3 immunohistochemistry was performed in an automated DAKO platform in the same way as clinical samples. All slides were counterstained with hematoxylin, dehydrated, and cover slipped.

This article is protected by copyright. All rights reserved. 


\section{Analysis of immunohistochemical staining}

Tumor cells were analyzed for ZBTB16 immunoreactivity in a semiquantitative way. Each histologic component of the mixed GCT, when present, was independently evaluated. Histologic patterns/subtypes of YST were assessed individually for their immunoreactivity with ZBTB16, AFP and GPC-3, respectively. Only nuclear staining for ZBTB16 and cytoplasmic staining for AFP and GPC-3 were considered positive. Based on the extent of the immunoreactivity, the staining was graded as: virtually no ( $<1 \%$ cells) staining (negative), $1-$ $25 \%$ of cells staining (focal), $25 \%-50 \%$ of cells staining (moderate extent) and $>50 \%$ of cell staining (extensive/diffuse). For ZBTB16, normal testicular tissue sections containing ZBTB16-positive spermatogonial cells and ZBTB16-negative stromal cells were used as positive and negative testing controls, respectively.

\section{RESULTS}

\section{Expression of ZBTB16 in metastatic YST}

Twenty-nine of the 32 metastatic YSTs showed immunoreaction with ZBTB16: 13/32 (41\%) had diffuse, 9/32 (28\%) had moderate, and 7/32 (22\%) had focal nuclear expression. Three (9\%) cases had no immunoreactivity with ZBTB16 (1 reticular, 1 solid, and 1 polyvesicular). ZBTB16 reactivity/grade appeared not associated with specific histologic growth patterns. In 15 cases of the mixed GCTs, all non-YST GCT components (teratoma and/or embryonal carcinoma) were nonreactive with ZBTB16 $(0 / 15,0 \%)$. The overall sensitivity of ZBTB16 in detecting metastatic YST was 29/32 (91\%). Seven of 8 (88\%) postchemotherapy metastatic YSTs were immunoreactive for ZBTB16 with 50\% (4/8) of the cases exhibiting diffuse cell staining, $25 \%$ (2/8) with moderate extent of cell staining, and $13 \%(1 / 8)$ with focal cell staining. Only one (13\%) postchemotherapy metastatic YST did not stain. Twenty-two of $24(92 \%)$ metastatic YSTs without prior treatment were positive for 
ZBTB16 with $38 \%(9 / 24)$ of the cases showing diffuse, $29 \%(7 / 24)$ moderate, and $15 \%$ (6/24) focal staining. Only two cases (8\%) were nonreactive. ZBTB16 showed no statistically significant difference in sensitivity for detecting metastatic YSTs between the non-treated and the chemotherapy treated YSTs $(\mathrm{p}<0.005)$. The results of ZBTB16 expression in extragonadal primary and metastatic YSTs are summarized in Table 1. Immunohistochemical expression of ZBTB16 in a representative case of metastatic YSTs is illustrated in figure 1. The overall sensitivity of ZBTB16 in detecting primary extragonadal YST was 100\% (4/4). The overall sensitivity of ZBTB16 in detecting both metastatic YST and extragonadal YST was $91.6 \%(33 / 36)$.

\section{Expression of ZBTB16 in extragonadal YST:}

The 4 extragonadal primary YSTs presented either as solid pattern, partially glandular or a mixture of both, mimicking moderately to poorly differentiated somatic malignancies. All the 4 extragonadal primary YSTs were strongly and diffusely reactive with ZBTB16 (4/4, 100\%). Figure 2 illustrates a liver primary YST (hematoxylin-eosin) and immunohistochemical expression of ZBTB16 in tumor cells. The results of ZBTB16 immunohistochemical expression in the metastatic YST-containing GCTs and primary extragonadal YSTs are summarized in table 1.

\section{Comparison of the immunoreactivity of ZBTB16 with AFP and GPC3}

Of the thirty-two cases of metastatic YSTs in our case series, twenty-nine were available for immunohistochemical study with AFP and GPC3. The results are summarized in table 2. The detecting sensitivity of ZBTB16, AFP and GPC-3 for those 29 cases was $89.7 \%, 58.6 \%$ and $86.2 \%$, respectively. Although there was no association in the immunoreactivity of AFP and GPC-3 with specific YST histologic patterns, AFP displayed a 
trend for nonreactivity in solid. Both AFP and GPC3 were nonreactive in the sarcomatoid YST case, with which, interestingly, ZBTB16 showed focal reactivity. Nevertheless, those pattern-related immunoreactivity differences warrant further validation with a larger number of cases.

\section{Expression of ZBTB16 in somatic malignancies}

We have previously demonstrated that ZBTB16 nuclear expression was absent in most of the somatic carcinomas, except reactivity in prostate cancers and weak and focal positivity in approximately one third of hepatocellular carcinomas $(23,28)$. With the exception of occasional ZBTB16 positive myoepthelial cells in the salivary gland carcinomas (adenoid cystic and acinar cell carcinoma), all the 51 somatic malignancies in this study were negative for ZBTB16. These results indicate that ZBTB16 is highly specific for YST. The results of ZBTB16 expression in the somatic malignancies are summarized in table 3.

\section{DISCUSSION}

It is estimated that $3 \%$ to $5 \%$ of newly diagnosed cancers present without established primary sites (29). YST notoriously displays diverse histologic patterns, which can mimic many different types of tumors - GCTs and somatic malignancies alike. Proliferative or hyperplastic endodermal glandular epithelium of teratoma and somatic adenocarcinoma can be mistaken for glandular YST $(2-4,30)$. Seminoma and poorly differentiated somatic malignancies can be simulated by solid YST (31), particularly in small biopsies or suboptimal specimens. In later recurrence of GCTs, YST commonly presents as a glandular and/or solid tumor, which, without prior clinical information, may lead to erroneous diagnosis of a somatic-type malignancy. All those make YST one of the most challenging malignancies to diagnose, particularly in the setting of extragonadal location and unknown clinical history. 
Distinction of YST from other GCTs (especially metastatic teratoma and seminoma) as well as from somatic malignancies is of critical importance because of different implications for treatment as well as prognosis and tumor biomarker surveillance. For example, metastatic teratoma is usually treated by surgery alone, while the presence of YST requires additional adjuvant chemotherapy (32-34). Furthermore, presence of YST in metastases increases the chances of recurrence despite additional therapy and portends an overall worse prognosis. Sensitive and specific markers for YST are therefore extremely valuable in helping reach correct diagnosis and informing optimal management strategy.

AFP is a useful traditional marker for YST, nevertheless, it is limited by low sensitivity with an immunoreactive positive rate as low as $60 \%$ (11). In addition, its staining is frequently focal and patchy $(9,35)$, contributing to false negative immunoreactivity in small biopsy specimens $(9,35)$. AFP has also been reported to stain embryonal carcinoma and teratoma $(36,37)$ as well as somatic tumors, such as ovarian serous adenocarcinoma $(38)$, clear cell adenocarcinoma (9), pancreatic adenocarcinomas (7), hepatocellular carcinoma (8), and gastric carcinoma (39)

GPC-3 is another GCT marker that was recently identified to be valuable for diagnosis of YST. It has been reported that GPC-3 is more sensitive than AFP $(12,14)$, but might not be as specific as AFP for YST. Expression of GPC-3 has been reported in embryonal carcinoma, choriocarcinoma, and teratoma as well as somatic tumors, including hepatocellular, gastric, and lung carcinomas (12, 14-17).

In our previous study, we have showed that ZBTB16 is highly sensitive and specific for testicular YST (40). In this current study, we further demonstrated that ZBTB16 was also a sensitive marker for extragonadal and metastatic YSTs with an overall sensitivity of $91.6 \%$, superior to AFP and GPC-3.

This article is protected by copyright. All rights reserved. 
Although ZBTB16 is expressed in some somatic tumors, including low grade and a portion of high grade prostatic carcinoma (23), some carcinoid tumor (26) as well as about $30 \%$ of hepatocellular carcinomas (with focal and weak positivity) (28), ZBTB16 nuclear expression is rarely seen in other somatic malignancies, particularly the common insidious and specific-marker-lacking malignancies, such as pancreatobilliary and upper gastrointestinal carcinomas. Due to the availability of tissue specific markers for prostatic carcinoma, hepatocellular carcinoma and carcinoid tumor, distinction of YST from these ZBTB16-expressing somatic tumors should be less problematic. ZBTB16 is, therefore, an excellent adjunct marker with high sensitivity and specificity in distinguishing extra-testicular primary YST as well as metastatic YST from its mimics. The other advantage of ZBTB16 is its nuclear staining which makes it easy to interpret. Unlike the cytoplasmic staining of AFP and GPC-3, nuclear ZBTB16 immunostaining is less affected by hemorrhage, serum and secretions, or necrosis, thus the background staining is minimal. Moreover, when necessary, ZBTB16 in paneling with other GCT markers (e.g. SALL4, AFP or GPC-3) should further increase the sensitivity and confidence in the diagnosis of YST for challenging cases.

In summary, the results of this study demonstrate that ZBTB16 is a novel sensitive and specific nuclear marker in the detection of metastatic and extragonadal YSTs.

\section{ACKNOWLEDGEMENTS}

Author contributions: GQX and MTI designed the project, the main conceptual ideas and proof outline. GQX drafted the manuscript. DSP and QY collected the samples and data and performed the study. DSP, MTI, CW and MA analyzed the results and revised the draft.

\section{Conflicts of interest}

The authors declare no competing financial interests.

This article is protected by copyright. All rights reserved. 


\section{REFERENCES}

1. Einhorn L. Chemotherapeutic and surgical strategies for germ cell tumors. Chest Surg Clin N Am. 2002;12:695-706.

2. Ye H, Ulbright TM. Difficult differential diagnoses in testicular pathology. Arch Pathol Lab Med 2012;136: 435-446.

3. Kao CS, Idrees MT, Young RH et al. Solid pattern yolk sac tumor: a morphologic and immunohistochemical study of 52 cases. Am J Surg Pathol 2012;36: 360-367.

4. Magers MJ, Kao CS, Cole CD et al. "Somatic-type" malignancies arising from testicular germ cell tumors: a clinicopathologic study of 124 cases with emphasis on glandular tumors supporting frequent yolk sac tumor origin. Am J Surg Pathol. 2014;38:1396-1409

5. Cao D, Li J, Guo CC et al. SALL4 is a novel diagnostic marker for testicular germ cell tumors. Am J Surg Pathol 2009;33:1065-1077.

6. Bahrami A, Ro JY, Ayala AG. An overview of testicular germ cell tumors. Arch Pathol Lab Med 2007;131: 1267-1280

7. Mostofi FK. Histological change ostensibly induced by therapy in the metastasis of germ cell tumors of testis. Prog Clin Biol Res 1985;203:47-60.

8. Zynger DL, McCallum JC, Luan C et al. Glypican-3 has a higher sensitivity than alphafetoprotein for testicular and ovarian yolk sac tumour: immunohistochemical investigation with analysis of histological growth patterns. Histopathology 2010;56:750-757

9. Nojima T, Kojima T, Kato H, Sato T, Koito K, Nagashima K. Alpha-fetoprotein-producing acinar cell carcinoma of the pancreas. Hum Pathol. 1992;23:828-830.

This article is protected by copyright. All rights reserved. 
10. Sato K, Tanaka M, Kusaba T, Fukuda H, Tanikawa K. Immunohistochemical demonstration of alpha-fetoprotein in small hepatocellular carcinoma. Oncol Rep. 1998;5:355- 358.

11. Esheba GE, Pate LL, Longacre TA. Oncofetal protein GPC- 3 distinguishes yolk sac tumor from clear cell carcinoma of the ovary. Am J Surg Pathol. 2008;32:600-607.

12. Preda $\mathrm{O}$, Nicolae A, Aneiros-Fernández $\mathrm{J}$ et al. Glypican 3 is a sensitive, but not a specific, marker for the diagnosis of yolk sac tumours. Histopathology 2011;58: 312-314. 13. Zynger DL, Dimov ND, Luan C et al. Glypican 3: a novel marker in testicular germ cell tumors. Am J Surg Pathol 2006;30:1570-1575.

14. Zynger DL, Everton MJ, Dimov ND et al. Expression of glypican 3 in ovarian and extragonadal germ cell tumors. Am J Clin Pathol 2008;130:224-230.

15. Yamauchi N, Watanabe A, Hishinuma M et al. The glypican 3 oncofetal protein is a promising diagnostic marker for hepatocellular carcinoma. Mod Pathol 2005;18:1591-1598. 16. Saikali Z, Sinnett D. Expression of glypican 3 (GPC3) in embryonal tumors. Int J Cancer 2000;89:418-422.

17.Toretsky JA, Zitomersky NL, Eskenazi AE et al. Glypican-3 expression in Wilms tumor and hepatoblastoma. J Pediatr Hematol Oncol 2001;23:496-499.

18. Nogales FF, Quiñonez E, López-Marín L, Dulcey I, Preda O. A diagnostic immunohistochemical panel for yolk sac (primitive endodermal) tumours based on an immunohistochemical comparison with the human yolk sac tumor. Histopathology 2014;65(1):51-9).

19. Suliman BA, Xu D, Williams BR. The promyelocytic leukemia zinc finger protein: two decades of molecular oncology. Front Oncol 2012;2:74-96.

This article is protected by copyright. All rights reserved. 
20. Kolesnichenko M, Vogt PK. Understanding PLZF: two transcriptional targets, REDD1 and smooth muscle $\alpha$ - actin, define new questions in growth control, senescence, self-renewal and tumor suppression. Cell Cycle 2011;10:771-775

21. Brunner G, Reitz M, Schwipper V et al. Increased expression of the tumor suppressor PLZF is a continuous predictor of long-term survival in malignant melanoma patients. Cancer Biother Radiopharm 2008;23:451-459.

22. Cheung M, Pei J, Pei Y et al. The promyelocytic leukemia zinc-finger gene, PLZF, is frequently downregulated in malignant mesothelioma cells and contributes to cell survival. Oncogene 2010;29:1633-1640.

23. Xiao GQ, Unger P, Yang Q et al. Loss of PLZF expression in prostate cancer by immunohistochemistry correlates with tumor aggressiveness and metastasis. PLoS ONE 2015;10:e0121318.

24. Costoya JA, Hobbs RM, Barna M et al. Essential role of Plzf in maintenance of spermatogonial stem cells. Nat Genet 2004;36:653-659.

25. Song HW, Wilkinson MF. Transcriptional control of spermatogonial maintenance and differentiation. Semin Cell Dev Biol 2014;30:14-26.

26. Hechtman JF, Beasley MB, Kinoshita Y, Ko HM, Hao K, Burstein DE. Promyelocytic leukemia zinc finger and histone H1.5 differentially stain low- and high-grade pulmonary neuroendocrine tumors: a pilot immunohistochemical study. Hum Pathol. 2013;44(7):1400-5. 27. Straub S, Unger PD, Yang Q et al. Preferential expression of PLZF in benign prostatic epithelium and low grade prostate cancer. Mod Pathol 2015;28:261A.

28. Abu-Farsakh SH, Gonzalez RS, Yang Q, Xiao GQ. Down-regulation of PLZF in Hepatocellular Carcinoma

Abstracts and Case Studies From the College of American Pathologists 2016 Annual Meeting (CAP16). Arch Pathol Lab Med: 2016; 140 (9): e2-e244. 
29. Haineswoth JD, Greco FA. Management of patients with cancer of unknown primary site. Oncology. 2000;14:563-574.

30. Ulbright TM. The most common, clinically significant misdiagnoses in testicular tumor pathology, and how to avoid them. Adv Anat Pathol 2008;15:18-27.

31 Ulbright TM, Young RH. Seminoma with tubular, microcystic and related patterns: a study of 28 cases of unusual morphologic variants that often cause confusion with yolk sac tumor. Am J Surg Pathol 2005;29:500-505.

32. Sonneveld DJ, Sleijfer DT, Koops HS et al. Mature teratoma identified after postchemotherapy surgery in patients with disseminated nonseminomatous testicular germ cell tumors: a plea for an aggressive surgical approach. Cancer 1998;82:1343-1351.

33. Fizazi K, Tjulandin S, Salvioni R et al. Viable malignant cells after primary chemotherapy for disseminated nonseminomatous germ cell tumors: prognostic factors and role of postsurgery chemotherapy - results from an international study group. J Clin Oncol 2001;19:2647-2657.

34. Einhorn LH, Williams SD, Chamness A et al. High-dose chemotherapy and stem-cell rescue for metastatic germ-cell tumors. N Engl J Med 2007;357:340-348..

35. Dengfeng Cao, MD, PhD1; Peter A. Humphrey, MD, PhD1; and Robert W. Allan, MD. Specific Marker for Metastatic Germ Cell Tumors, With Particular Utility in Detection of Metastatic Yolk Sac Tumors. Cancer 2009;115:2640-51.

36. Fowler JE Jr, Sesterhenn I, Stutzman RE et al. Localization of alpha-fetoprotein and human chorionic gonadotropin to specific histologic types of nonseminomatous testicular cancer. Urology 1983;22:649-654.

37. Wittekind C, Wichmann T, Von Kleist S. Immunohistological localization of AFP and HCG in uniformly classified testis tumors. Anticancer Res 1983;3: 327-330.

This article is protected by copyright. All rights reserved. 
38. Higuchi Y, Kouno T, Teshima H, et al. Serous papillary cystadenocarcinoma associated with alpha-fetoprotein production. Arch Pathol Lab Med. 1984;108:710-712.

39. Sun N, Sun Q, Liu Q, Zhang T, Zhu Q, Wang W, Cao M, Zang QI. a-fetoproteinproducing gastric carcinoma: A case report of a rare subtype and literature review. Oncol Lett. 2016;11(5):3101-3104

40. Xiao GQ, Li F, Unger PD, Katerji H, Yang Q, McMahon L, Burstein DE. ZBTB16: a novel sensitive and specific biomarker for yolk sac tumor. Mod Pathol. 2016;29(6):591-8

\section{TABLES}

Table 1: Immunohistochemical expression of ZBTB16 in primary extragonadal YSTs and metastatic YST-containing GCTs

Table 2. Immunohistochemical expression of ZBTB16 in somatic malignancies

Table 3. Growth patterns and immunoreactivity of metastatic YSTs with ZBTB16, AFP and GPC-3. 


\section{FIGURE LEGENDS}

Figure 1: Expression of ZBTB16 in metastatic YST: A (Hematoxylin and Eosin) and B (immunohistochemistry) - Moderate extent of ZBTB16 positivity in metastatic retroperitoneal YST with reticular pattern. C (Hematoxylin and Eosin) and D (immunohistochemistry) - Diffuse ZBTB16 immunoreactivity in metastatic mediastinal YST with mostly solid growth pattern. E (Hematoxylin and Eosin) and F (immunohistochemistry)

- Metastatic omental mixed germ cell tumor showing focal YST element being highlighted by ZBTB16 immunostaining.

Figure 2: Expression of ZBTB16 in primary liver YST from a 76 year-old male. A and B (Hematoxylin and Eosin, low and high magnification) - Poorly differentiated carcinoma with vague glandular formation. C (Immunohistochemistry) - Diffuse and strong immunoreactivity of tumor cells with ZBTB16.

This article is protected by copyright. All rights reserved. 
Table 1: Immunohistochemical expression of ZBTB16 in primary extragonadal YSTs and metastatic YST-containing GCTs

\begin{tabular}{|c|c|c|c|c|c|}
\hline Diagnosis and \%YST in GCT & $\begin{array}{l}\text { number of } \\
\text { cases }\end{array}$ & $\begin{array}{l}\text { Composition } \\
\text { of GCT }\end{array}$ & Location & $\begin{array}{l}\text { ZBTB16 Positivity } \\
\text { of YST element }\end{array}$ & $\begin{array}{l}\text { ZBTB16 positivity } \\
\text { of non-YST element }\end{array}$ \\
\hline \multicolumn{6}{|l|}{ Primary extragonadal YST } \\
\hline $100 \%$ YST (pure YST) & 4 & YST (4/4) & $\begin{array}{l}\text { Retroperitoneum (1/4) } \\
\text { Mediastinum (1/4) } \\
\text { Liver (1/4) } \\
\text { Bladder (1/4) }\end{array}$ & $3+(4 / 4 ; 100 \%)$ & NA \\
\hline \multicolumn{6}{|c|}{ Metastatic mixed GCT, no chemotherapy } \\
\hline $\mathrm{YST}<50 \%$ & 6 & $\begin{array}{l}\mathrm{T}+\mathrm{EC}+\mathrm{YST}(3 / 6) \\
\mathrm{T}+\mathrm{YST}(3 / 6)\end{array}$ & Retroperitoneal LN (6/6) & $\begin{array}{l}3+(1 / 6 ; 17 \%) \\
2+(3 / 6 ; 50 \%) \\
1+(2 / 6 ; 33 \%)\end{array}$ & $0(0 / 6,0 \%)$ \\
\hline $\mathrm{YST} \geq 50 \%$ & 18 & $\begin{array}{l}\text { YST }(14 / 18) \\
\text { T+YST }(3 / 18) \\
\text { EC+YST }(1 / 18)\end{array}$ & $\begin{array}{l}\text { Retroperitoneal LN (10/18) } \\
\text { Mediastinal LN (4/18) } \\
\text { Abdomen }(2 / 18) \\
\text { Lung }(1 / 18) \\
\text { Pelvic LN }(1 / 18)\end{array}$ & $\begin{array}{l}3+(8 / 18 ; 44 \%) \\
2+(4 / 18 ; 22 \%) \\
1+(4 / 18 ; 22 \%) \\
0 \quad(2 / 18 ; 11 \%)\end{array}$ & $0(0 / 4,0 \%)$ \\
\hline \multicolumn{6}{|c|}{ Metastatic mixed GCT, postchemotherapy } \\
\hline $\mathrm{YST}<50 \%$ & 2 & $\mathrm{~T}+\mathrm{YST}(2 / 2)$ & $\begin{array}{l}\text { Retroperitoneal LN (1/2) } \\
\text { Renal vein (1/2) }\end{array}$ & $\begin{array}{l}3+(1 / 2 ; 50 \%) \\
1+(1 / 2 ; 50 \%)\end{array}$ & $0(0 / 2,0 \%)$ \\
\hline $\mathrm{YST} \geq 50 \%$ & 6 & $\begin{array}{l}\text { YST }(3 / 6) \\
\text { T+YST }(1 / 6) \\
\text { T+EC+YST (1/6) } \\
\text { EC+YST }(1 / 6)\end{array}$ & $\begin{array}{l}\text { Retroperitoneal LN (4/6) } \\
\text { Mediastinal LN }(1 / 6) \\
\text { Pelvic LN }(1 / 6)\end{array}$ & $\begin{array}{l}3+(3 / 6 ; 50 \%) \\
2+(2 / 6 ; 33 \%) \\
0 \quad(1 / 6 ; 17 \%)\end{array}$ & $0(0 / 3,0 \%)$ \\
\hline
\end{tabular}

GCT = germ cell tumor YST = yolk sac tumors $; E C=$ embryonal carcinoma; $T$ = teratoma; $L N=$ lymph node

This article is protected by copyright. All rights reserved. 
Table 2: Growth patterns and immunoreactivity of metastatic YSTs with ZBTB16, AFP and GPC-3

\begin{tabular}{|c|c|c|c|c|}
\hline Case No & Tumor growth patterns & ZBTB16 & AFP & GPC-3 \\
\hline 1 & Myxomatous & $2+$ & $3+$ & $2+$ \\
\hline 2 & Reticular+macrocystic & $2+$ & Neg & $2+$ \\
\hline 3 & Sarcomatoid & $1+$ & Neg & Neg \\
\hline 4 & Reticular & $3+$ & $3+$ & $3+$ \\
\hline 5 & Polyvesicular + glandular & $3+$ & $2+$ & $2+$ \\
\hline 6 & Endodermal sinus+reticular & $3+$ & $3+$ & $2+$ \\
\hline 7 & Reticular +glandular & $2+$ & $3+$ & $2+$ \\
\hline 8 & Reticular & $3+$ & $3+$ & $2+$ \\
\hline 9 & Reticular & $1+$ & Neg & $1+$ \\
\hline 10 & Endodermal sinus +papillary & $3+$ & $3+$ & $3+$ \\
\hline 11 & Myxomatous & $1+$ & $1+$ & $1+$ \\
\hline 12 & Reticular & $3+$ & $\mathrm{Neg}$ & $1+$ \\
\hline 13 & Reticular & $3+$ & $3+$ & $3+$ \\
\hline 14 & Solid+endodermal sinus & $2+$ & $2+$ & $2+$ \\
\hline 15 & Polyvesicular+ macrocystic & $2+$ & $2+$ & $2+$ \\
\hline 16 & Reticular & Neg & Neg & $1+$ \\
\hline 17 & Reticular & $1+$ & $\mathrm{Neg}$ & Neg \\
\hline 18 & Papillary & $3+$ & Neg & $2+$ \\
\hline 19 & Reticular+glandular & $1+$ & Neg & $2+$ \\
\hline 20 & Reticular & $3+$ & Neg & $3+$ \\
\hline 21 & Glandular & $2+$ & $1+$ & $1+$ \\
\hline 22 & Solid & Neg & $\mathrm{Neg}$ & $1+$ \\
\hline 23 & Polyvesicular+ reticular & $3+$ & $3+$ & $1+$ \\
\hline 24 & Polyvesicular & $\mathrm{Neg}$ & $1+$ & Neg \\
\hline 25 & Solid & $2+$ & Neg & $3+$ \\
\hline 26 & Glandular+ reticular & $2+$ & Neg & $1+$ \\
\hline 27 & Endodermal sinus & $1+$ & $2+$ & Neg \\
\hline 28 & Myxomatous & $1+$ & $1+$ & $1+$ \\
\hline 29 & Endodermal sinus & $3+$ & $2+$ & $2+$ \\
\hline
\end{tabular}

Neg. negative

This article is protected by copyright. All rights reserved. 
Table 3: Immunohistochemical expression of ZBTB16 in additional somatic malignancies

\begin{tabular}{|c|c|c|}
\hline Diagnosis & \# of cases & ZBTB16 immunoreactivity \\
\hline Breast carcinoma & 8 & Negative \\
\hline Melanoma & 8 & Negative \\
\hline Lymphoma & 5 & Negative \\
\hline Pancreatobilliary carcinoma & 3 & Negative \\
\hline $\begin{array}{l}\text { Combined small cell } \\
\text { carcinoma and urothelial } \\
\text { carcinoma }\end{array}$ & 6 & Negative \\
\hline Salivary gland carcinoma & 7 & $\begin{array}{l}\text { Negative, occasional } \\
\text { myoepithelial cell positive }\end{array}$ \\
\hline Mesothelioma & 3 & Negative \\
\hline Adrenocortical carcinoma & 1 & Negative \\
\hline Synovial sarcoma & 2 & Negative \\
\hline Renal cell carcinoma & 2 & Negative \\
\hline Mullerian carcinoma & 2 & Negative \\
\hline Colorectal carcinoma & 2 & Negative \\
\hline Meckel cell carcinoma & 2 & \begin{tabular}{|l|} 
Negative \\
\end{tabular} \\
\hline
\end{tabular}

This article is protected by copyright. All rights reserved. 


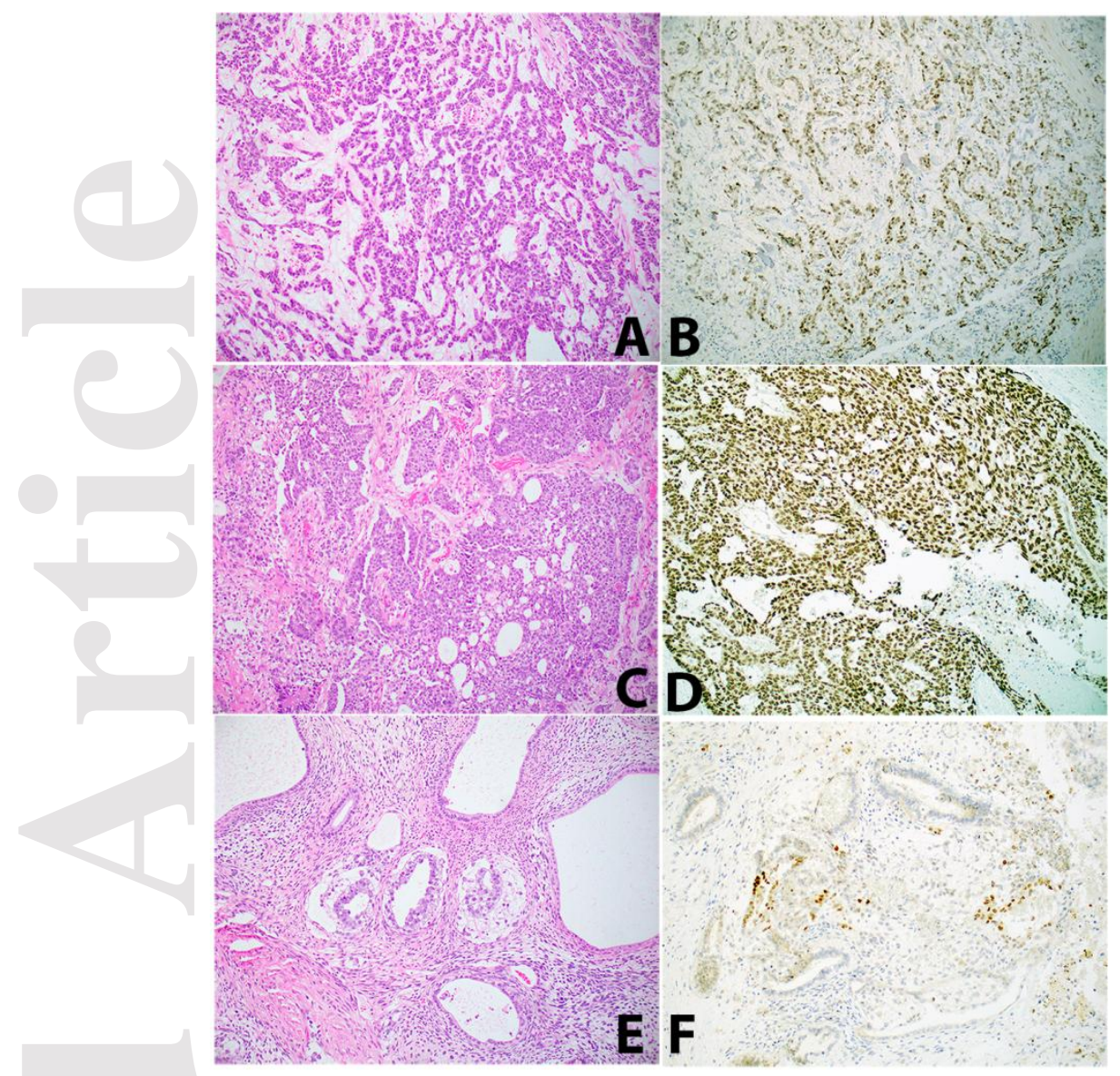

This article is protected by copyright. All rights reserved. 


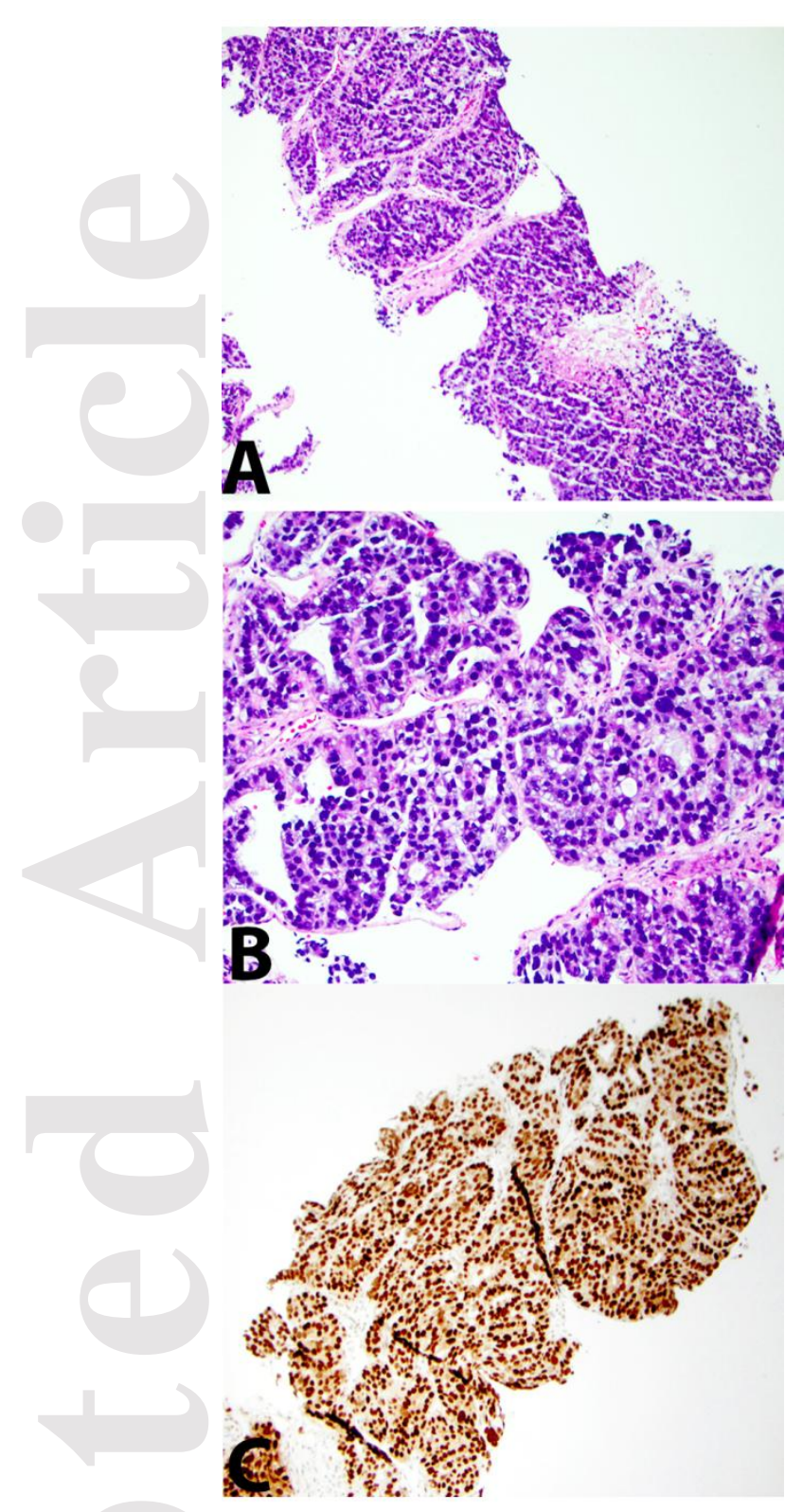

This article is protected by copyright. All rights reserved. 